\title{
DYNAMIC RESPONSES COUPLED ANALYSIS OF FPSO IN SOUTH CHINA SEA
}

\author{
Ting Guo ${ }^{1}$, Hongde Qin ${ }^{2}$ \\ 1,2 College of Shipbuilding Engineering \\ Harbin Engineering University \\ Harbin, 150001, China \\ E-mail:3153829702@qq.com
}

\begin{abstract}
The far-flung ocean has abundant resource and the exploitation area of ocean oil and gas is developing from offshore to deepwater and ultra-deepwater following the increase demand for oil and gas resource. Therefore, one of the floating structures for deepwater exploitation is FPSO. In this article, the coupling hydrodynamic problems of FPSO and mooring system have been studied and analyzed by using the three dimensional potential theory, the FPSO's mooring system is simulated by slender rod theory. In the $1500 \mathrm{~m}$ deepwater, calculated and analyzed the hydrodynamic and motion of six-Degree of Freedom (6DOF) of FPSO and mooring lines' load of FPSO at the fairlead. Then compared the result of our program with software Ariane by BV, it can be seen that the result of program conform to the actual needs. Therefore, use the program to calculate the hydrodynamic response of Single Point Mooring (SPM) FPSO in South China Sea with the wind/wave/flow. The results indicate that the sway/roll/yaw of SPM-FPSO are quite well while surge motion is a little large. The static and dynamic analysis of FPSO's mooring system is calculated, when the direction of wave/wind accord with the motion, the force of mooring lines at fairlead reach maximum while the moment is minimum.
\end{abstract}

Keywords: Coupling Hydrodynamic, Mooring System, Static Analysis, Dynamic Analysis

\section{Introduction}

The far-flung ocean has abundant resource and the exploitation area of ocean oil and gas is developing from offshore to deepwater and ultra-deepwater following the increase demand for oil and gas resource. In terms of situation in China, the South China Sea have abundant resource, the oil and gas exploration and development has great potential. There are four classic offshore are utilized [1], they are TLP (Tension Leg Platform), SPAR, SemiSubmersible Platform and FPSO. FPSO has low cost, short construction period, portable and oil/gas storage capacity, so FPSO received extensive attention of the industry. To solve the hydrodynamic of FPSO is one of the most important problems. The coupling analyze of FPSO and its mooring system, FPSO and its turret.

The FPSO is assumed undergoing six-Degree of Freedom (6DOF) motions under the external environmental loads, such as wind/wave/current forces. The natural frequency of FPSO's surge/sway/yaw is low, FPSO will generate significant movement when effect of wave drift force. Approximation methods for calculating the difference frequency force was presented by Newman [2], in the case of calculate the difference frequency force without second-order velocity potential. It can be save the calculation time effectively. The motion response analysis of FPSO with turret was presented by Wichers [3-5], but regardless the dynamic effect of the mooring lines and risers to FPSO hull. Huse and Matsumoto ${ }^{[6]}$ propose the dominant mechanisms by through static water attenuation test which shows damping of mooring lines belongs low frequency energy dissipation. Aranha [7, 8] consider the effect of wave drift with flow velocity. Fine and Grue [9] obtain the damping of low frequency yaw by solve the radiation/diffraction problem with low speed. Yang and Teng [10-12] developed a full time domain analysis method to calculate the wave force and the result accurately to second-order. Recently, there are three models were used to simulate mooring line, such as the lumped mass model, the catenary model and slender rod model. Koterayma [13] obtained the result of frequency domain and time domain by lumped mass model. The three-dimensional slender rod theory was presented by Garret [14] to calculate the dynamic performance of the floating structure and mooring system. Kim, Soo, Young [15] to study the nonlinear dynamic response of mooring lines by Newmark method. In order to solve the coupling problem of floating structure and mooring system, mainly adopts the time domain analysis and frequency domain analysis [16-20]. 
In this paper, we use the three-dimensional potential theory to compute the hydrodynamic coefficients, motion response of 6DOF, then calculate the load of mooring lines at fairlead by use slender rod theory in the dynamic analysis and static analysis, respectively [21-24].

\section{Hydrodynamic of FPSO and Slender Rod Theory}

\section{- Potential theory}

The Cartesian coordinate system $(x, y, z)$ is established on the static water surface, the $z$-axis oriented positively upward. The velocity potential equation can be given according to the ideal fluid assumptions:

$\Delta \Phi=\frac{\partial^{2} \Phi}{\partial x^{2}}+\frac{\partial^{2} \Phi}{\partial y^{2}}+\frac{\partial^{2} \Phi}{\partial z^{2}}=0$

Where the $\Phi$ is velocity potential.

Nonlinear free-surface condition and wavesurface equation are:

$$
\begin{aligned}
& \left\{\frac{\partial^{2} \Phi}{\partial t^{2}}+g \frac{\partial \Phi}{\partial z}+2 \nabla \Phi \nabla \frac{\partial^{2} \Phi}{\partial z^{2}}=0\right\}_{z=\eta} \\
& \eta=\left\{-\frac{1}{g}\left(\frac{\partial \Phi}{\partial t}+\frac{1}{2} \nabla \Phi \bullet \nabla \Phi\right)\right\}_{z=\eta}
\end{aligned}
$$

The velocity potential satisfy the boundary conditions of the seabed is:

$\frac{\partial \Phi}{\partial z}=0 \quad z=-h$

The $h$ indicate the water depth. The velocity potential also satisfy the corresponding to the bodysurface condition and the radiation condition. In order to solve the velocity potential and keep to the second-order items by perturbation expansion when the hypothesis of slight wave.

$$
\begin{aligned}
& \Phi=\varepsilon \phi^{(1)}+\varepsilon^{2} \phi^{(2)}+\mathrm{O}\left(\varepsilon^{3}\right) \\
& \eta=\varepsilon \eta^{(1)}+\varepsilon^{2} \eta^{(2)}+\mathrm{O}\left(\varepsilon^{3}\right)
\end{aligned}
$$

Where $\varepsilon=k A$ is perturbation coefficient, $k$ indicate the wave number, $A$ is wave amplitude.

To solve the equations (2) and (3) by Taylor series expansion when $z=0$, then substitute the equations (5) and (6) into equation of free-surface, respectively.

$$
\begin{aligned}
& \eta^{(1)}=-\frac{1}{g} \frac{\partial \phi^{(1)}}{\partial t} \\
& \eta^{(2)}=-\frac{1}{g} \frac{\partial \phi^{(2)}}{\partial t}-\frac{1}{2 g} \nabla \phi^{(1)} \nabla \phi^{(1)}+\frac{1}{g^{2}} \frac{\partial \phi^{(1)}}{\partial t} \frac{\partial^{2} \phi^{(1)}}{\partial z \partial t}
\end{aligned}
$$

$$
\begin{aligned}
& \frac{\partial^{2} \phi^{(1)}}{\partial t^{2}}+g \frac{\partial \phi^{(1)}}{\partial z}=0 \\
& \frac{\partial^{2} \phi^{(2)}}{\partial t^{2}}+g \frac{\partial \phi^{(2)}}{\partial z}=-2 \nabla \phi^{(1)} \nabla \frac{\partial \phi^{(1)}}{\partial t}+\frac{1}{g} \frac{\partial \phi^{(1)}}{\partial t}\left(\frac{\partial^{3} \phi^{(1)}}{\partial t^{2} \partial z}+g \frac{\partial^{2} \phi^{(1)}}{\partial t^{2}}\right)
\end{aligned}
$$

\section{- $\quad$ Slender rod theory}

The slender rod model has strongly versatility, it can be simulate the mooring line and flexible bar such as marine riser, and better computation efficiency and precision.

The equilibrium equation of slender rod section can be provided by Newton's second law and moment equilibrium conditions.

$$
\begin{aligned}
& q+F^{\prime}=\rho \ddot{r}(s, t) \\
& M^{\prime}+r^{\prime} \times F+m=0
\end{aligned}
$$

Where, $q$ is uniform external load by per unit, $F$ is the shear stress on the unit, $M$ is bending moment on the unit, $m$ is torque by per unit, $r^{\prime}$ indicate the tangent direction of unit vector on the bar, $r(s, t)$ is the displacement of pole central-line.

Assumption for uniform distribution, the axial stiffness of the total moment as follows:

$M=r^{\prime} \times E I r^{\prime \prime}+H r^{\prime}$

Where $E I$ and $H$ indicate flexural rigidity and torque on the bar, respectively.

Combine the equations (12) and (13) can obtain the equation as follows:

$$
r^{\prime} \times\left[\left(E I r^{\prime \prime}\right)^{\prime}+F\right]+H^{\prime} r^{\prime}+H r^{\prime \prime}+m=0
$$

Then dot product $r$ ' for equation (14), that is:

$H^{\prime}+m r^{\prime}=0$

When $H=0, m=0$, the equation (15) can be written as:

$r^{\prime} \times\left[\left(E I r^{\prime \prime}\right)^{\prime}+F\right]=0$

Post-multiplication $r^{\prime}$ for equation (16), can be obtained as:

$$
\begin{aligned}
& r^{\prime} \times\left[\left(E I r^{\prime \prime}\right)^{\prime}+F\right] \times r^{\prime}=0 \\
& {\left[\left(E I r^{\prime \prime}\right)^{\prime}+F\right]-\left(r^{\prime} *\left[\left(E I r^{\prime \prime}\right)^{\prime}+F\right]\right) * r^{\prime}=0}
\end{aligned}
$$

Assumption the mooring line elongation is:

$\left(r^{\prime} * r^{\prime}\right)=(1+\varepsilon)^{2}$

Let,

$$
\lambda=r^{\prime} *\left[\left(E I r^{\prime \prime}\right)^{\prime}+F\right]=T-E I \kappa^{2}
$$

Where, $F=-\left(E I r^{\prime \prime}\right)^{\prime}+\lambda r^{\prime}, \kappa$ is the curvature of mooring line, $T$ indicate the tension of mooring line.

So the governing equation of slender rod is:

$-\left(E I r^{\prime \prime}\right) "+\left(\lambda r^{\prime}\right)^{\prime}+q=\rho \ddot{r}(s, t)$

The equation (20) and (18) are the basic governing equations of mooring line's static analysis and dynamic analysis. 


\section{Results and Discussion}

The table 1 shows the main parameters of FPSO in this study. Fig. 1 shows the model of FPSO in this research.

Table 1. The main parameters of FPSO

\begin{tabular}{|c|c|}
\hline Lpp (m) & 310.0 \\
\hline Breadth at waterline (m) & 47.17 \\
\hline Draft (m) & 18.90 \\
\hline Vertical CoG above keel (m) & 13.32 \\
\hline Longitudinal CoG in front of Lpp/2 (m) & 6.83 \\
\hline Displacement (kg) & $2.3862 \mathrm{E}+08$ \\
\hline Roll radius of gyration (m) & 14.77 \\
\hline Pitch radius of gyration (m) & 77.47 \\
\hline Yaw radius of gyration (m) & 79.30 \\
\hline Turret elevation below FPSO keel (m) & 84.62 \\
\hline Turret position (in front of Longitudinal CoG) (m) & 1.52 \\
\hline Front wind area (m $\left.{ }^{2}\right)$ & 15.85 \\
\hline Transverse wind area (m $\left.{ }^{2}\right)$ & 1012 \\
\hline
\end{tabular}

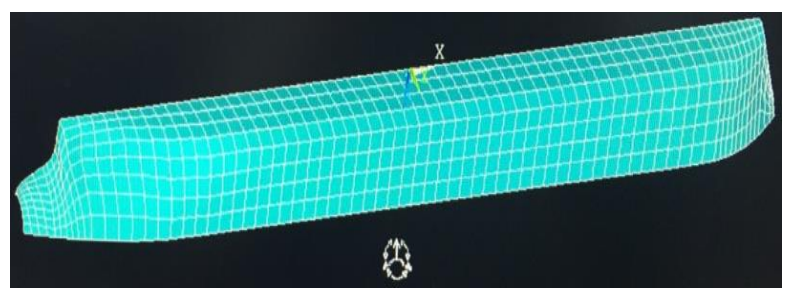

Figure 1. Model of FPSO
- The analysis of 6DOF motions response of FPSO

There is six Degree of Freedom motions for FPSO under the external environmental loads, such as surge, sway, heave, roll, pitch and yaw. The table 2 gives us the statistic of 6DOF motions of FPSO. The Mean is short for mean value, Std is short for standard deviation, Max is short for maximum and Min indicate minimum.

Table 2. The statistic of 6DOF motions of FPSO

\begin{tabular}{|c|c|c|c|c|}
\hline Motion & Mean & Std & Max & Min \\
\hline Surge (m) & $-0.10062 \mathrm{E}+03$ & $0.10083 \mathrm{E}+02$ & $-0.68745 \mathrm{E}+02$ & $-0.13326 \mathrm{E}+03$ \\
\hline Sway (m) & $0.32006 \mathrm{E}-07$ & $0.17342 \mathrm{E}-06$ & $0.61843 \mathrm{E}-06$ & $-0.42536 \mathrm{E}-06$ \\
\hline Heave (m) & $-0.56944 \mathrm{E}+01$ & $0.11908 \mathrm{E}+01$ & $-0.13261 \mathrm{E}+01$ & $-0.10015 \mathrm{E}+02$ \\
\hline Roll (deg) & $0.20025 \mathrm{E}-09$ & $0.88863 \mathrm{E}-08$ & $0.58196 \mathrm{E}-07$ & $-0.61182 \mathrm{E}-07$ \\
\hline Pitch (deg) & $0.55386 \mathrm{E}-01$ & $0.12915 \mathrm{E}+01$ & $0.45927 \mathrm{E}+01$ & $-0.46059 \mathrm{E}+01$ \\
\hline Yaw (edg) & $-0.38013 \mathrm{E}-07$ & $0.17102 \mathrm{E}-06$ & $0.44091 \mathrm{E}-06$ & $-0.47798 \mathrm{E}-06$ \\
\hline
\end{tabular}

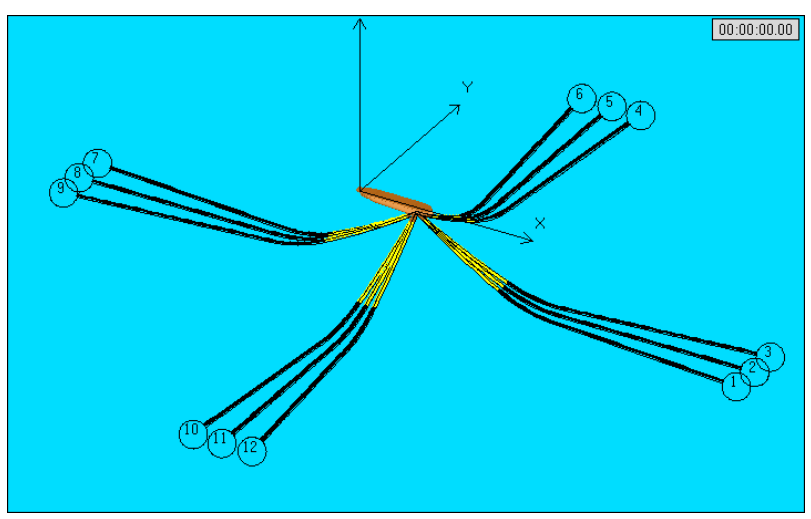

Figure 2. The layout configuration of turret mooring system 

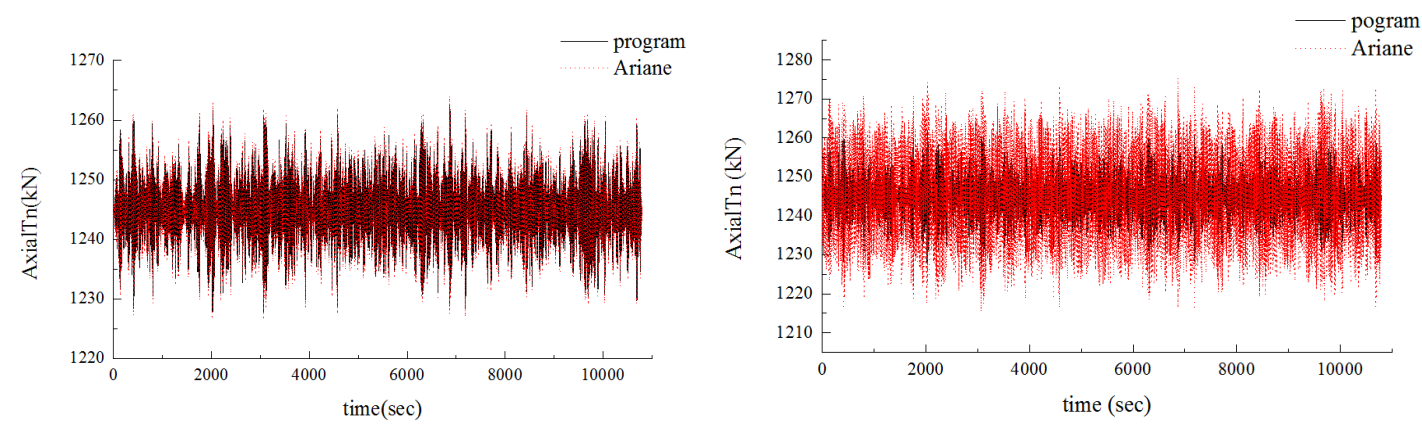

Mooring 1 Mooring 5
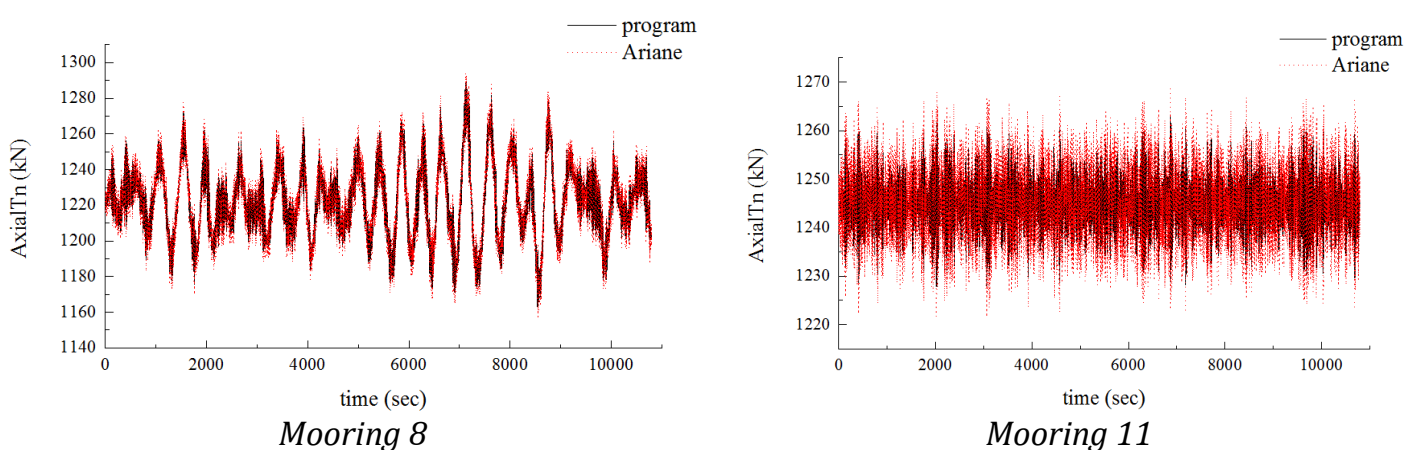

Figure 3. The mooring force comparison between our program and Ariane software

Form the table 2 it can be observed that the FPSO undergoes significant slow drift surge motion. Our program estimates the varying drift forces and the damping of hull of hydrodynamic. Form table 2 we can see the amplitude of sway and roll are small, because of the length of FPSO is so long. Form the statistic, it can be seen the angle of yaw is small because of the FPSO has the vane effect with the turret's exist. On account of the vane effect, FPSO can work in head-sea at almost any time, it provide the stability and safety of FPSO.

The hull is moored with 12 mooring lines. The mooring lines are divided into four groups with 90 degrees interval, each group consists of 3 lines with 5 degrees interval to each other. Fig. 2 shows the lay out configuration of the whole mooring system. Tab. 2 presents the parameters of mooring lines.

Firstly, we obtained the hydrodynamic coefficients of FPSO by Hydro-STAR, and computed the 6DOF motions' RAO (Response Amplitude Operator). Moreover, we loaded the data from Hydro-STAR such as added mass, damping coefficient and 6DOF motions' RAO into Ariane software to compute the load of FPSO's mooring line at fairlead. Fig. 3 shows the curve of time history that is comparison of our program and Ariane software.

Firstly, the length of single mooring line is 1500 $\mathrm{m}$, the mooring lines are attached at the location of turret. Fig. 1 gives us the layout configuration of the mooring system. Using the dynamic response model of the FPSO, the FPSO's response in head irregular waves is simulated and compared with the software
Ariane by BV. In our program, the JONSWAP sea spectrum is used, the significant wave height hs = $4.2 \mathrm{~m}$, spectral peak period $\mathrm{Tp}=14.0 \mathrm{~s}$ and the spectral peak factor $\gamma=2.3$. The program simulation are 54000 steps and the time step solution of FPSO is $0.2 \mathrm{~s}$. The simulation is performed at heading seas.

During the comparison the irregular wave time history is generated in our program and Ariane software in order to ensure the two methods have the same incident wave time history.

The following Fig. 3 show us the comparison results of mooring system from that of our program with that of Ariane. It can be seen from the comparison that the results from our program agree quite well with that from Ariane software. The mooring tensions of $1 \#$ which is in the windward side and is the most loaded lines, the mooring tensions of $8 \#$ which is in the leeward side.

From the comparison of $1 \#, 5 \#, 8 \#, 11 \#$ mooring lines it is shown that our program can estimates the mooring lines force at fairleads of the FPSO are correctly. From the results of Fig. 3, it can be seen that the most loaded line shows a combination tension response from wave frequency and low frequency range.

\section{- The hydrodynamic analysis of FPSO in South China Sea}

In addition, our program is used to compute the hydrodynamic of FPSO in South China Sea. The environment of South China Sea simulated by the JONSWAP sea spectrum, the significant wave height 
$\mathrm{hs}=12.9 \mathrm{~m}$, spectral peak period $\mathrm{Tp}=16.1 \mathrm{~s}$ and the spectral peak factor $\gamma=2.0$. The API wind spectrum, viscous flow load by empirical equation of Ocimf and wave drift damping of floating structure are used in this example. Table 3 provide the statistic of FPSO's 6DOF motions.

From table3 it is shown the sway/roll of FPSO is quite well, and the yaw is pretty good. The mean value of yaw is $-3.66 \times 10-8 \mathrm{deg}$, and the stander deviation is $1.33 \times 10-7$, while the surge of FPSO is a little large, the mean value is $-1.01 \times 102 \mathrm{~m}$. Because of the vane effect, the performance of yaw motion quite well, and the model length let the FPSO has a good commend of sway and roll motion. From the surge statistic shows us the FPSO in the head sea at most time.

It is needed to ensure the equilibrium position and initial form at static load when dynamic analysis of mooring system. To solve the initial position and form, then compute the equilibrium position by it.

Table 4-7 provide the load at fairlead of statistic of mooring lines by static analysis and dynamic analysis, they are mooring 2 , mooring 5 , mooring 8 and mooring 11. The F_X F_Y and F_Z are force in $x y$ and $\mathrm{z}$ directions, respectively, M_X M_Y and M_Z are moment in $\mathrm{x} y$ and $\mathrm{z}$ directions, respectively, and the Axial Tn indicate the tension of axial direction of mooring line at fairlead in table 4-7.

The mooring 2 and 8 are in head-sea and following-sea, respectively, and mooring 5 and 11 are located on either side of FPSO.

Table 3. Statistic of FPSO's 6DOF motions

\begin{tabular}{|c|c|c|c|c|}
\hline Motion & Mean & Std & Max & Min \\
\hline Surge $(\mathrm{m})$ & $-1.01 \mathrm{E}+02$ & $9.25 \mathrm{E}+00$ & $-7.24 \mathrm{E}+01$ & $-1.30 \mathrm{E}+02$ \\
\hline Sway $(\mathrm{m})$ & $2.82 \mathrm{E}-08$ & $1.41 \mathrm{E}-07$ & $6.05 \mathrm{E}-07$ & $-3.32 \mathrm{E}-07$ \\
\hline Heave $(\mathrm{m})$ & $-5.69 \mathrm{E}+00$ & $1.18 \mathrm{E}+00$ & $-9.56 \mathrm{E}-01$ & $-1.03 \mathrm{E}+01$ \\
\hline Roll $(\mathrm{deg})$ & $2.19 \mathrm{E}-10$ & $7.35 \mathrm{E}-09$ & $6.17 \mathrm{E}-08$ & $-4.69 \mathrm{E}-08$ \\
\hline Pitch $(\mathrm{deg})$ & $5.61 \mathrm{E}-02$ & $1.29 \mathrm{E}+00$ & $5.03 \mathrm{E}+00$ & $-4.53 \mathrm{E}+00$ \\
\hline Yaw $(\mathrm{deg})$ & $-3.66 \mathrm{E}-08$ & $1.33 \mathrm{E}-07$ & $3.00 \mathrm{E}-07$ & $-4.15 \mathrm{E}-07$ \\
\hline
\end{tabular}

Table 4. The statistic of mooring 2

Table 4. The statistic of mooring 2
\begin{tabular}{|c|c|c|c|c|c|c|c|}
\hline & $\begin{array}{c}\text { F_X } \\
(\mathrm{N})\end{array}$ & $\begin{array}{c}\text { F_Y }_{-} \\
(\mathrm{N})\end{array}$ & $\begin{array}{c}\text { F_Z } \\
(\mathrm{N})\end{array}$ & $\begin{array}{c}\text { M_X } \\
(\mathrm{N} \cdot \mathrm{m})\end{array}$ & $\begin{array}{c}\text { M_Y } \\
(\mathrm{N} \cdot \mathrm{m})\end{array}$ & $\begin{array}{c}\text { M_Z } \\
(\mathrm{N} \cdot \mathrm{m})\end{array}$ & AxialTn $(\mathrm{N})$ \\
\hline Mean & 923861.4 & $4.5 \mathrm{E}-06$ & -1058123 & 0.007299 & 77604534 & 0.042495 & 1405096 \\
\hline Std & 98610.4 & 0.000131 & 60939.28 & 0.03279 & 4511886 & 0.190903 & 110853.1 \\
\hline Max & 1292124 & 0.000374 & -888148 & 0.102888 & 97731850 & 0.599015 & 1819079 \\
\hline Min & 666522.4 & -0.00037 & -1280669 & -0.09132 & 63758422 & -0.53164 & 1110593 \\
\hline
\end{tabular}

\begin{tabular}{|c|c|c|c|c|c|c|c|}
\hline & $\begin{array}{c}\text { F_X } \\
(\mathrm{N})\end{array}$ & $\begin{array}{c}\text { F_Y } \\
(\mathrm{N})\end{array}$ & $\begin{array}{c}\text { F_Z } \\
(\mathrm{N})\end{array}$ & $\begin{array}{c}\text { M_X } \\
(\mathrm{N} \cdot \mathrm{m})\end{array}$ & $\begin{array}{c}\text { M_Y } \\
(\mathrm{N} \cdot \mathrm{m})\end{array}$ & $\begin{array}{c}\text { M_Z } \\
(\mathrm{N} \cdot \mathrm{m})\end{array}$ & AxialTn (N) \\
\hline Mean & 812026.3 & 0.000859 & -997083 & 0.012448 & 74013755 & 0.072474 & 1285937 \\
\hline Std & 90642.98 & 0.019399 & 103311.5 & 0.287824 & 7573709 & 1.67572 & 137170.8 \\
\hline Max & 1051843 & 0.437108 & -805420 & 6.485114 & 96949361 & 37.75656 & 1651546 \\
\hline Min & 650726.1 & -0.00275 & -1278645 & -0.04223 & 60041487 & -0.24585 & 1035445 \\
\hline
\end{tabular}

Table 5. The statistic of mooring 5

Table 5. The statistic of mooring 5
\begin{tabular}{|c|c|c|c|c|c|c|c|}
\hline & $\begin{array}{c}\text { F_X } \\
(\mathrm{N})\end{array}$ & $\begin{array}{c}\text { F_Y } \\
(\mathrm{N})\end{array}$ & $\begin{array}{c}\text { F_Z } \\
(\mathrm{N})\end{array}$ & $\begin{array}{c}\text { M_X } \\
(\mathrm{N} \cdot \mathrm{m})\end{array}$ & $\begin{array}{c}\text { M_Y } \\
(\mathrm{N} \cdot \mathrm{m})\end{array}$ & $\begin{array}{c}\text { M_Z } \\
(\mathrm{N} \cdot \mathrm{m})\end{array}$ & AxialTn $(\mathrm{N})$ \\
\hline Mean & 6292.811 & 782581.1 & -969324 & 11613503 & 83622505 & 67614223 & 1245831 \\
\hline Std & 4135.45 & 15059.07 & 12421.77 & 223476.5 & 1387579 & 1301088 & 19124.04 \\
\hline Max & 19413.27 & 838028.2 & -927225 & 12436338 & 88460944 & 72404796 & 1316143 \\
\hline Min & -6656.44 & 731777.6 & -1014840 & 10859580 & 78487256 & 63224853 & 1181226 \\
\hline \multicolumn{7}{|c|}{ Dynamic analysis of mooring 5 } \\
\hline Mean & 1736.631 & 779980.6 & -966252 & 11574912 & 83446018 & 67389543 & 1241802 \\
\hline Std & 7111.958 & 71565.83 & 88317.96 & 1062037 & 7721270 & 6183216 & 113645.3 \\
\hline Max & 40820.68 & 974443.9 & -738368 & 14460748 & $1.04 \mathrm{E}+08$ & 84190982 & 1549099 \\
\hline Min & -26800.2 & 596673 & -1204549 & 8854627 & 63903322 & 51551947 & 949321.8 \\
\hline
\end{tabular}


Table 6. The statistic of mooring 8

Static analysis of mooring 8

\begin{tabular}{|c|c|c|c|c|c|c|c|}
\hline & $\begin{array}{c}\text { F_X } \\
(\mathrm{N})\end{array}$ & $\begin{array}{c}\text { F_Y }_{-} \\
(\mathrm{N})\end{array}$ & $\begin{array}{c}\text { F_Z } \\
(\mathrm{N})\end{array}$ & $\begin{array}{c}\text { M_X } \\
(\mathrm{N} \cdot \mathrm{m})\end{array}$ & $\begin{array}{c}\text { M_Y } \\
(\mathrm{N} \cdot \mathrm{m})\end{array}$ & $\begin{array}{c}\text { M_Z } \\
(\mathrm{N} \cdot \mathrm{m})\end{array}$ & AxialTn (N) \\
\hline Mean & -669075 & $1.72 \mathrm{E}-05$ & -892420 & -0.00718 & 87019072 & -0.04179 & 1115735 \\
\hline Std & 73428.29 & 0.000101 & 51105.04 & 0.022889 & 5266036 & 0.133262 & 84930.38 \\
\hline Max & -447023 & 0.000492 & -727864 & 0.053329 & $1.05 \mathrm{E}+08$ & 0.310481 & 1441743 \\
\hline Min & -952639 & -0.00018 & -1082213 & -0.10759 & 70947295 & -0.62637 & 854175 \\
\hline
\end{tabular}

Dynamic analysis of mooring 8

\begin{tabular}{|c|c|c|c|c|c|c|c|}
\hline & $\begin{array}{l}\text { F_X } \\
(\mathrm{N})\end{array}$ & $\begin{array}{l}F_{-} Y \\
(\mathrm{~N})\end{array}$ & $\begin{array}{l}\text { F_Z } \\
(\mathrm{N})\end{array}$ & $\begin{array}{c}\text { M_X } \\
(\mathrm{N} \cdot \mathrm{m})\end{array}$ & $\begin{array}{c}\mathrm{M}_{-} \mathrm{Y} \\
(\mathrm{N} \cdot \mathrm{m})\end{array}$ & $\begin{array}{c}\text { M_Z } \\
(\mathrm{N} \cdot \mathrm{m})\end{array}$ & AxialTn (N) \\
\hline Mean & -763986 & 0.000474 & -952906 & 0.007309 & 93649022 & 0.042551 & 1221521 \\
\hline Std & 127094.8 & 0.010575 & 117702.9 & 0.157037 & 11690709 & 0.914278 & 172035.4 \\
\hline Max & -562398 & 0.151539 & -699537 & 2.252462 & $2.92 \mathrm{E}+08$ & 13.11391 & 4272386 \\
\hline Min & -3177532 & -0.03517 & -2855971 & -0.52115 & 69600853 & -3.03418 & 912921.1 \\
\hline
\end{tabular}

Table 7. The statistic of mooring 11

Static analysis of mooring 11

\begin{tabular}{|c|c|c|c|c|c|c|c|}
\hline & $\begin{array}{c}\mathrm{F}_{-} \mathrm{X} \\
(\mathrm{N})\end{array}$ & $\begin{array}{c}\mathrm{F}_{-} \mathrm{Y} \\
(\mathrm{N})\end{array}$ & $\begin{array}{c}\text { F_Z } \\
(\mathrm{N})\end{array}$ & $\begin{array}{c}\text { M_X } \\
(\mathrm{N} \cdot \mathrm{m})\end{array}$ & $\begin{array}{c}\text { M_Y } \\
(\mathrm{N} \cdot \mathrm{m})\end{array}$ & $\begin{array}{c}\text { M_Z } \\
(\mathrm{N} \cdot \mathrm{m})\end{array}$ & AxialTn (N) \\
\hline Mean & 6292.811 & -782581 & -969324 & $-1.2 \mathrm{E}+07$ & 83622505 & $-6.8 \mathrm{E}+07$ & 1245831 \\
\hline Std & 4135.45 & 15059.07 & 12421.77 & 223476.6 & 1387579 & 1301088 & 19124.04 \\
\hline Max & 19413.27 & -731778 & -927225 & $-1.1 \mathrm{E}+07$ & 88460944 & $-6.3 \mathrm{E}+07$ & 1316143 \\
\hline Min & -6656.44 & -838028 & -1014840 & $-1.2 \mathrm{E}+07$ & 78487256 & $-7.2 \mathrm{E}+07$ & 1181226 \\
\hline
\end{tabular}

Dynamic analysis of mooring 11

\begin{tabular}{|c|c|c|c|c|c|c|c|}
\hline & $\begin{array}{c}\text { F_X }_{-} \\
(\mathrm{N})\end{array}$ & $\begin{array}{c}\mathrm{F}_{-} \mathrm{Y} \\
(\mathrm{N})\end{array}$ & $\begin{array}{c}\mathrm{F}_{-} \mathrm{Z} \\
(\mathrm{N})\end{array}$ & $\begin{array}{c}\text { M_X } \\
(\mathrm{N} \cdot \mathrm{m})\end{array}$ & $\begin{array}{c}\text { M_Y } \\
(\mathrm{N} \cdot \mathrm{m})\end{array}$ & $\begin{array}{c}\text { M_Z } \\
(\mathrm{N} \cdot \mathrm{m})\end{array}$ & AxialTn (N) \\
\hline Mean & 1736.63 & -779981 & -966252 & $-1.2 \mathrm{E}+07$ & 83446017 & $-6.7 \mathrm{E}+07$ & 1241802 \\
\hline Std & 7111.957 & 71565.8 & 88317.93 & 1062037 & 7721268 & 6183214 & 113645.2 \\
\hline Max & 40820.66 & -596673 & -738368 & -8854627 & $1.04 \mathrm{E}+08$ & $-5.2 \mathrm{E}+07$ & 1549099 \\
\hline Min & -26800.2 & -974444 & -1204549 & $-1.4 \mathrm{E}+07$ & 63903322 & $-8.4 \mathrm{E}+07$ & 949321.8 \\
\hline
\end{tabular}

It can be seen from table 4-7, the force is maximum at the fairlead when motion in the same direction with wind and wave, while the moment is the minimum, such as the force in $\mathrm{x}$-axis direction in table 4 and table 6. However, the force is the minimum when motion direction and wind/wave direction angle of 90 degrees, such as force of $y$-axis direction in table 4 and table 6 .

The force of Single Point Moored (SPM) FPSO in zaxis direction has a little change form numerical. From the numerical on the table 4 and table 6 , it can be obtained that the z-axis direction's moment of mooring 2 and mooring 8 is minimum on the wave direction while the motion of mooring 5 and mooring 11 is larger than mooring 2 and mooring 8 . It is not hard to see that the z-axis direction's displacement of mooring 2 and mooring 8 is negligibly small.

The statistic of four classic mooring lines is provided by table 4-7 and the force analysis at fairlead by static analysis and dynamic analysis. Based on the environment of South China Sea, the effect of FPSO with the wave/wind/current and mooring line are considered.

Compared with the static analysis, dynamic analysis can not only consider the linear and weak nonlinear factors on the influence of the mooring system, but also to consider strongly nonlinear factors.

To estimate the loads of floating structure in the actual state of sea more accuracy, it must be used the dynamic analysis.

\section{Conclusion}

The research develops a program to perform the dynamic coupled analysis of Single Point Moored FPSO with wind/wave/current and its mooring lines. Via comparison with the Ariane software, it can be concluded that the program in this research seems to be properly established. 
Then our program is used to compute the SPMFPSO work in South China Sea, and provide two analysis methods, they are static analysis and dynamic analysis. Furthermore, the statistic tables provide the differences of static analysis and dynamic analysis. To estimate the loads of floating structure in the actual state of sea more accuracy, it must be used the dynamic analysis.

\section{Acknowledgement}

The research is supported by The Project of the Fundamental Research for Provincial institutions of higher learning in Heilongjiang (No. 2017BJ11).

\section{References}

[1] Shi H S, Liu C G. The spar platform and considerations in concept design. China offshore platform, 2007, 22: 1-4.

[2] Newman J N. Second-order, slowly-varying forces on vessels in irregular waves. Mooring, 1974.

[3] Wichers J E, Sluijs M F. The influence of waves on the low-frequency hydrodynamic coefficients of moored vessels // Offshore Technology Conference. 1979.

[4] Wichers J E W. A simulation model for a single point moored tanker. Electrical Engineering Mathematics and Computer Science, 1988.

[5] Wichers J, Ji C. Behaviour of turret moored tankers in combined extreme metocean parameters // Offshore Technology Conference. 1997

[6] Huse E, Matsumoto K. Mooring Line Damping Due to First- and Second-Order Vessel Motion. Proc Annual Offshore Technology Conference, 1989.

[7] Aranha J A P, Paulo S. Wave groups and slow motion of an ocean structure //Proc. 6th Intern. Workshop on Water Waves and Floating Bodies, Woods Hole. 1991.

[8] Aranha J A P. A formula for 'wave damping' in the drift of a floating body. Journal of Fluid Mechanics, 1994, 275(4): 147-155.

[9] Finne S, Grue J. On the complete radiationdiffraction problem and wave-drift damping of marine bodies in the yaw mode of motion. Journal of Fluid Mechanics, 1998, 357(01): 289-320.

[10] Yang M D, Teng B, Gou Y, et al. Static analysis of mooring lines using nonlinear finite element method. Ocean Engineering, 2009, 27(2): 14-20.

[11] Yang M D, Teng B, Xiao L F, et al. Full timedomain nonlinear coupled dynamic analysis of a truss spar and its mooring/riser system in irregular wave. Science China Physics Mechanics and Astronomy, 2014, 57(1): 152-165.
[12] Yang M D, Teng B. Coupled Dynamic Analysis of a Moored Spar Platform in Time Domain// ASME 2010 29th International Conference on Ocean, Offshore and Arctic Engineering American Society of Mechanical Engineers, 2010: 461-467.

[13] Koterayama W. Motions of moored floating body and dynamic tension of mooring lines in regular waves. Research Institute for Applied Mechanics Bulletin, 1978, 26.

[14] Garrett D L. Dynamic analysis of slender rods. Journal of Energy Resources Technology, 1982, 104(4): 302-306.

[15] Nam-Ti Kim, Sang-Soo J, Moon-Young K. Nonlinear finite element analysis of ocean cables. China Ocean Engineering. 2004, 18(4).

[16] Tang Y G, Zhang R Y, Liu L Q, et al. Dynamic tension of mooring system in deep sea with finite element method. The Ocean Engineering, 2009: 10-15.

[17] Yuan M. Time domain nonlinear analysis of the mooring system of deep-water floating structures. Shanghai Jiao Tong University, Shanghai, 2011.

[18] Qi Q, Zhang T, Wen P, et al. Numerical simulation of FPSO mooring system based on AQWA. Ship Science and Technology, 2011, 33: 14-18.

[19] Zhang S G. Research and analysis on dynamic response of the mooring system of deepwater FPSO. Harbin Engineering University, Harbin, 2011.

[20] Zheng C R, Fan J, Miao G P. Coupled dynamic analysis of a deepwater FPSO in time domain. Chinese Journal of Hydrodynamics, 2012, 27.

[21] Lind, T., Yanyan, H. and Jappinen, $H$. Sustainability and energy efficiency in the pulp and paper industry. Paper Asia, 2016; 32(5): 1521.

[22] Yi, H, Nie, Z, and Li, B. Efficient implementations of Gaussian elimination in finite fields on Asics for MQ cryptographic systems. Journal of Discrete Mathematical Sciences and Cryptography, 2018, 21(3): 797-802.

[23] Chau, K, Zhu, Y, Shen, H, and Huang, S. A study on creative personality and innovation behaviorwell-being as the mediator. Journal of Interdisciplinary Mathematics, 2018, 21(2): 253264.

[24] Arjun, K S, and Rakesh, K. Mhd and heat transfer analysis of nanofluid flow past a vertical porous plate. Journal of Mechanical Engineering Research and Developments, 2017, 40(4):650659. 